\title{
Analysis of Spectra and Intensity of 3D Fluorescence of Phenol Dissolved in Water
}

\author{
Xiao Qianqian \\ College of Civil Engineering and Architecture, \\ Zhejiang University of Technology \\ Hangzhou, China \\ Queenxiao1314@sina.com
}

\section{Chen Fei}

College of Civil Engineering and Architecture, Zhejiang University of Technology

Hangzhou, China

lilichenfei123@foxmail.com

\author{
Zhou Yun \\ College of Civil Engineering and Architecture, \\ Zhejiang University of Technology \\ Hangzhou, China \\ zhouyunslow@hotmail.com
}

\author{
Chen Lei \\ College of Civil Engineering and Architecture, \\ Zhejiang University of Technology \\ Hangzhou, China \\ zj_chen_lei@sina.com
}

\author{
Li Jun* \\ College of Civil Engineering and Architecture, \\ Zhejiang University of Technology \\ Hangzhou, China \\ tanweilijun@zjut.edu.cn
}

\begin{abstract}
The technique of three dimension (3D) Fluorescence Spectra was used to rapidly analyze the concentration of phenol in waters. Distilled water and river water as solvents were prepared for standard Phenol liquids which were analyzed by fluorospectro photometer. With the concentration of phenol increases, the peak of fluorescence can be identified more clearly. The phenol in distilled water, correlation between concentration and fluorescence intensity is 0.999. The maximum fluorescence intensity at the characteristic wavelength of phenol replaced peak intensity to exclude the offset of the curve of peak intensity due to the fluorescence of low phenol concentration was affected by other fluorescence matters from river water, correlation is 0.9998. These results indicated that phenol concentration can be measured by fluorospectro photometer to monitor the phenol pollution in drinking water system.
\end{abstract}

Keywords-3D fluorescence spectra; phenol; fluorescence intensity; rapid measurement; drinking water system

\section{INTRODUCTION}

The situation of water pollution in China is still serious, with huge challenges to safe drinking water and sudden source water pollution problems arising frequently $[1$, 2].For instance, phenol leakage occurred in 2011, Hangzhou, China. It started with a car containing phenol in the upstream of the Qiantang River dumped, and then contamination was caused to the river and the city downstream of which had to stop water supply. Phenol has a strong corrosive effect to the skin and mucous membranes, and it can inhibit the central nervous system and damage the function of liver and kidney [3]. It is included in national drinking water criteria (GB5749-2006) that the provisions of volatile phenol is $0.002 \mathrm{mg} / \mathrm{L}$, and in national surface water criteria (GB3838-2002) is 0.005 $\mathrm{mg} / \mathrm{L}$. Thus, rapid and sensitive detection of variations of phenol in water is imperative . Currently, mainly detection methods of phenol are spectrophotometry, chromatography $[4,5]$, extraction separation $[6,7]$, liquid chromatography [8], and spectrometry, etc. The existing problems such as using toxic organic solvent extraction, fussy operation, and being time-consuming are in some of these methods as mentioned above .

Fluorescence technique has been rapidly developed for the new chemical analysis methods for the past 20 years. Because of being highly sensitive, not time-consuming and without reagent, fluorescence technique has been proved a simple, environmentally friendly analytic technique. 3D fluorescence spectroscopy can obtain fluorescence intensity information during the changes of excitation and emission wavelengths simultaneously, which provides more information and the fluorescence characteristics are more obvious compared to conventional spectroscopy. This technique has been applied to indicate the degree of organic pollution of sewage [9, 10], rivers [11, 12], lakes [13] and urban supply water [14] and so on.

As the phenol has strong fluorescence characteristics [15], this study aims to explore the 3D fluorescence characteristics of phenol in water, and the feasibility of rapid detection and judgments of phenol contamination when it appears.

\section{MATERIALS AND METHODS}

\section{A. Preparation of Samples}

$0.2000 \mathrm{~g}$ analytically pure of phenol was dissolved respectively in distilled water and raw water of Qiantang River, to make $2000 \mathrm{mg} / \mathrm{L}$ reserve liquid, and diluted to a series of gradient concentration. 


\section{B. Instrument}

F97Pro fluorescence spectrophotometer from Shanghai Technology Co., Ltd.

\section{Experimental procedure}

Preparation of water samples before fluorescence detection required microfiltration through $0.45-\mu \mathrm{m}$ membrane (the material of which is cellulose esters) to remove tiny particles, bacteria, and colloidal. The main operating parameters settings of the experiment are as follows: excitation wavelength scan range is $200-600 \mathrm{~nm}$, the excitation interval of the sampling is $10 \mathrm{~nm}$; emission wavelength scan range is $200-600 \mathrm{~nm}$, the scanning interval is $1 \mathrm{~nm}$, the scanning speed is $6000 \mathrm{~nm} / \mathrm{min}$; gain (PMT) is $900 \mathrm{~V}$.

\section{Data processing method}

The paper use MATLAB (2012R) to carry on the process of data from Excel documents generated after 3D fluorescence scanning.

To illustrate how to use MATLAB to process the data correctly from the Excel documents, here is some simple illustration of the procedure.

First load a series of the Excel documents generated after 3D fluorescence scanning into MATLAB. And then find the maximum of fluorescence intensity and the corresponding wavelength of certain areas in the spectra. The procedure can be done by MATLAB through some simple user-defined functions conveniently.

\section{RESULTS AND ANALYSIS}

\section{A. 3D fluorescence characteristics of phenol solution} prepared with distilled water

1) fluorescence spectra of different concentrations of phenol prepared with distilled water

FI and W is abbreviation of fluorescence intensity and wavelengths separately. As is shown in Fig .1 (a) that there is no significant fluorescence fingerprint in fluorescence spectra of distilled water. Fluorescence spectra of concentration of phenol solution from $0.002 \mathrm{mg} / \mathrm{L}$ to 1 $\mathrm{mg} / \mathrm{L}$ in Fig .1 (b) to (h) are shown above. Fluorescence spectrum of $0.002 \mathrm{mg} / \mathrm{L}$ solution of phenol has no obvious fingerprint. Fingerprint located at an excitation wavelength of $270 \mathrm{~nm}$ and emission wavelength of $290-305 \mathrm{~nm}$ first appears in Fig. 1 (c), which belongs to the class of proteinlike fluorescence spectra [16]. With the concentration of phenol increase, in the same position, fluorescence contour becomes dense and the color of the spectra becomes dark, which shows that the concentration of phenol and the color intensity and spectrum is positively correlated. The degree of contamination or the concentration of phenol can be qualitatively or quantitatively determined by comparing fingerprints position, contour lines and spectral intensity of the color.

2) The fluorescence intensity of different concentrations of phenol in distilled water

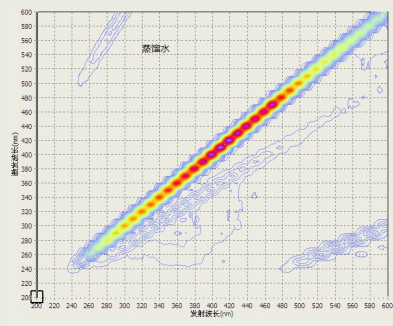

(a)

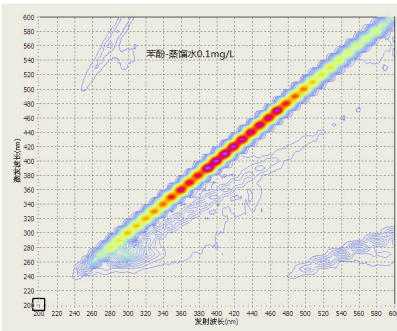

(e)

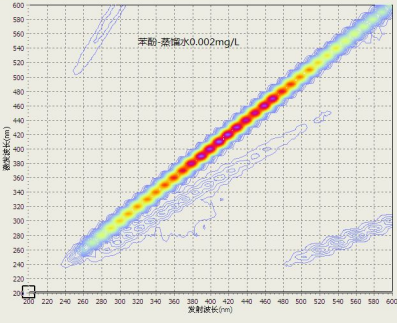

(b)

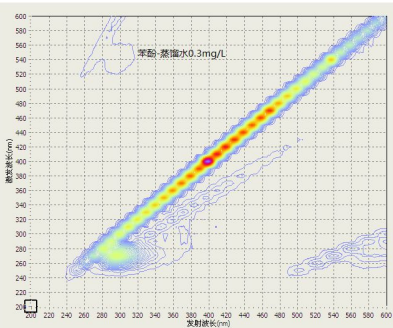

(f)

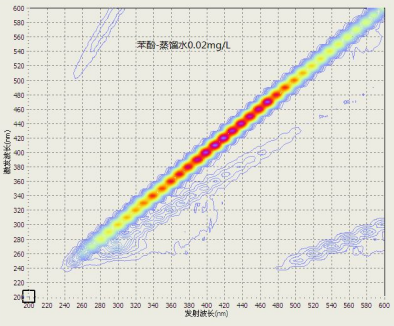

(c)

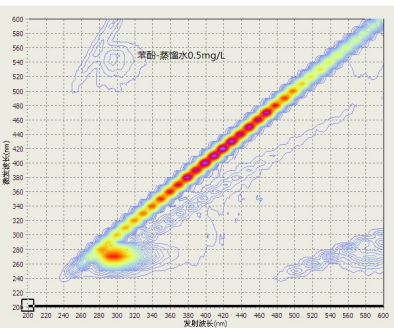

(g)

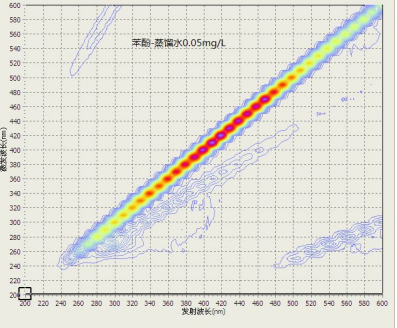

(d)

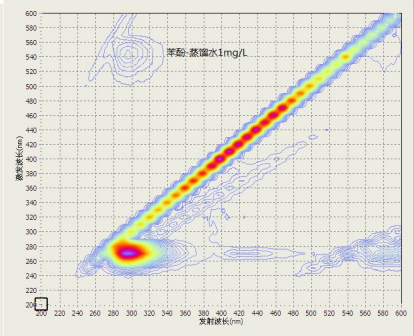

(h)

Figure 1. Fluorescence spectra of different concentration of phenol in drinking water.

(a) Distilled water; (b) Phenol in distilled water, $0.002 \mathrm{mg} / \mathrm{L}$; (c) Phenol in distilled water, 0.02mg/L; (d) Phenol in distilled water, $0.05 \mathrm{mg} / \mathrm{L}$; (e) Phenol in distilled water, $0.1 \mathrm{mg} / \mathrm{L}$;

(f) Phenol in distilled water, $0.3 \mathrm{mg} / \mathrm{L} ;$ (g) Phenol in distilled water, $0.5 \mathrm{mg} / \mathrm{L}$; (h) Phenol in distilled water, $1.0 \mathrm{mg} / \mathrm{L}$ 


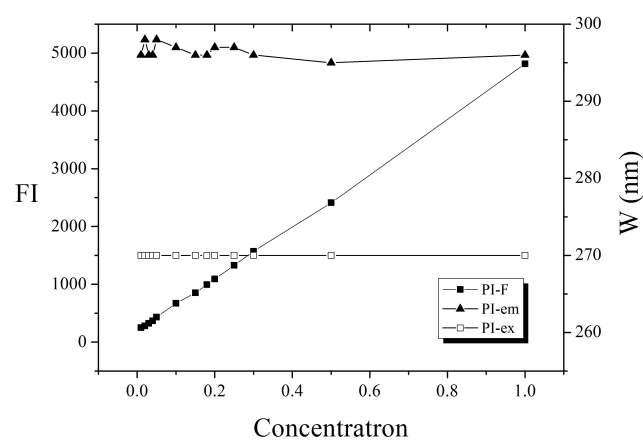

Figure 2. Fluorescence spectra of different concentration of phenol in drinking water.

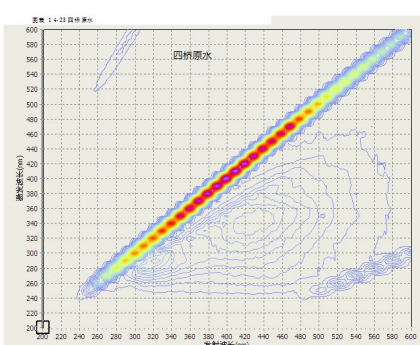

(a)

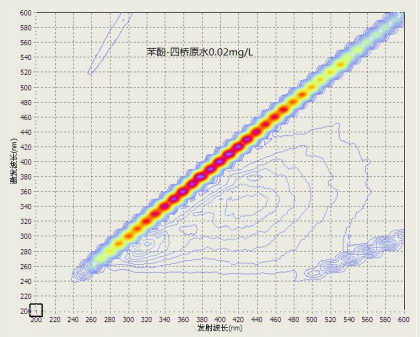

(c)

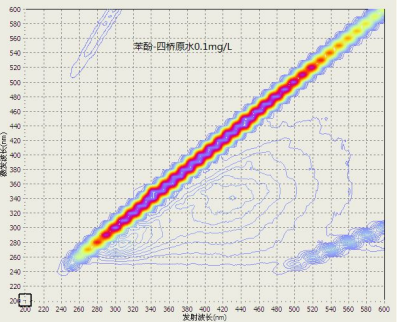

(e)

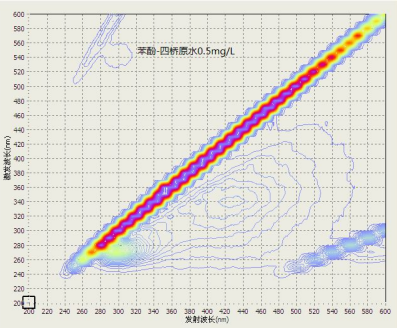

(g)

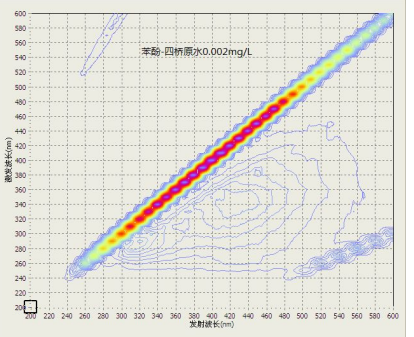

(b)

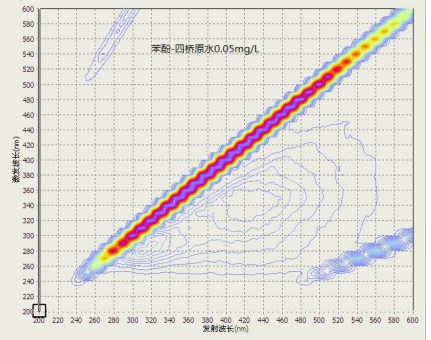

(d)

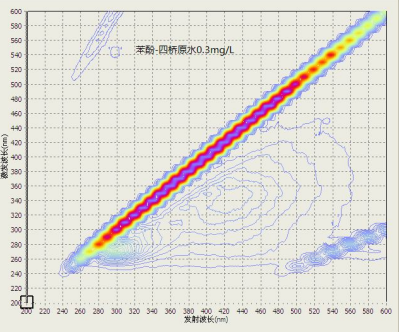

(f)

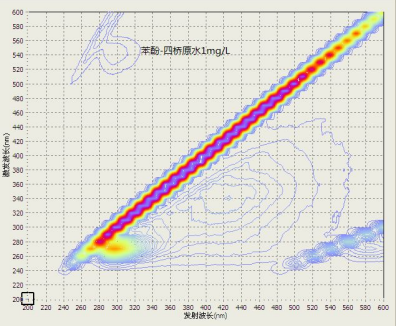

(h)
Figure 3. Fluorescence spectra of different concentration of phenol in drinking water.

(a) river water; (b)phenol- river water $0.002 \mathrm{mg} / \mathrm{L}$; (c) phenol- river water $0.02 \mathrm{mg} / \mathrm{L}$; (d) phenol- river water $0.05 \mathrm{mg} / \mathrm{L}$; (e)phenol- river water $0.1 \mathrm{mg} / \mathrm{L}$; (f)phenol- river water $0.3 \mathrm{mg} / \mathrm{L}$; (g) phenol- river water, $0.5 \mathrm{mg} / \mathrm{L}$; (h) phenol- river water $1 \mathrm{mg} / \mathrm{L}$
Different concentrations of phenol distilled fluorescence intensity are shown in Fig .2, we can seen that the response of the phosphor is 209.5 at $270 \mathrm{~nm} / 297 \mathrm{~nm}$ as the concentration of phenol is $0.002 \mathrm{mg} / \mathrm{L}$, while the fluorescence $270 \mathrm{~nm} / 297 \mathrm{~nm}$ response value at 4814 as the phenol concentration is $1.0 \mathrm{mg} / \mathrm{L}$. The fluorescence intensity increases as the concentration of phenol increases from $0.002 \mathrm{mg} / \mathrm{L}$ to $1.0 \mathrm{mg} / \mathrm{L}$. Actually, there is a strong linear relation between the fluorescence intensity and the concentration of phenol with the correlation coefficient of $r=0.999$. At different concentrations, the excitation wavelengths of fluorescence peak remain unchanged, while the emission wavelengths have a slight fluctuation when the concentration is between $0.002 \mathrm{mg} / \mathrm{L}$ and 0.2 $\mathrm{mg} / \mathrm{L}$.

\section{B. 3D fluorescence characteristics of the river phenol solution}

1) Different concentrations of phenol fluorescence spectrum prepared with river water

Fluorescence spectra of the river are shown in Fig .3 (a), we can see that water without adding phenol has two fluorescence peaks, peak $1 \mathrm{ex} / \mathrm{em}$ is $285-295 \mathrm{~nm} / 315-325$ $\mathrm{nm}$, belonging to the class of protein fluorescence peak; peak II ex/em is $325-360 \mathrm{~nm} / 410-450 \mathrm{~nm}$, fluorescence belonging to the class of humic-like peak [16]. Correspondingly, the color of fluorescence peaks of river water is lighter, and the fluorescence intensity comes lower.

Fluorescence spectra of phenol with the concentration between $0.002 \mathrm{mg} / \mathrm{L}$ and $1 \mathrm{mg} / \mathrm{L}$ are shown in Fig .3 (b) to (h). The fluorescence peaks of humic-like matters almost haven't changed in the fluorescence spectra, yet for the peaks of protein-like matters, with concentration increases, the fluorescence contour becomes denser and the color of spectra gets darker. That means the concentration of phenol and the color and density of spectrum contours is positively correlated. But the position of fluorescence peak shifts from $270 \mathrm{~nm} / 300 \mathrm{~nm}$ to $290 \mathrm{~nm} / 320 \mathrm{~nm}$ as the concentration of phenol decreases from $1 \mathrm{mg} / \mathrm{L}$ to $0 \mathrm{mg} / \mathrm{L}$.

2) The fluorescence intensity of different concentrations of phenol in water.

The fluorescence intensity of different concentrations of phenol in river water are shown in Fig .4, it can be seen, the water peak at $290 \mathrm{~nm} / 320 \mathrm{~nm}$ is belonging to the class of the protein-like peak, with the intensity value of which is 674.4 , indicating that the existence of protein-like matter of fluorescence in the river. As the concentration of phenol increases from $0.002 \mathrm{mg} / \mathrm{L}$ to $1.0 \mathrm{mg} / \mathrm{L}$, the fluorescence

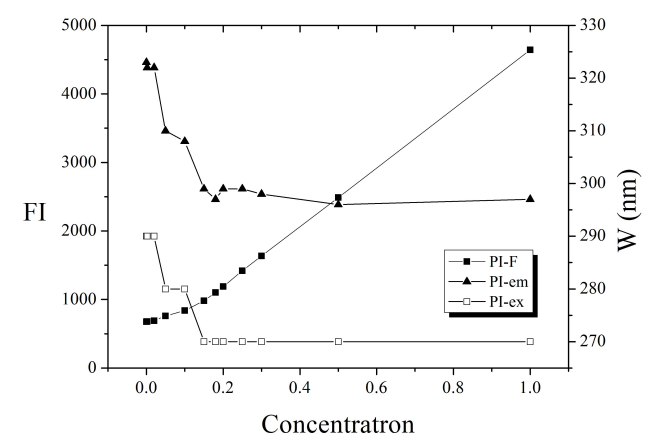

Figure 4. phenol-Forth Bridge protein-like fluorescence peak 
intensity increases. The linear correlation coefficient between the concentration and fluorescence intensity is 0.993 . When phenol concentration is from $0.002 \mathrm{mg} / \mathrm{L}$ to $0.2 \mathrm{mg} / \mathrm{L}$, the peak position of the fluorescence excitation wavelength and emission wavelength moves from the 290 $\mathrm{nm} / 320 \mathrm{~nm}$ to $270 \mathrm{~nm} / 290 \mathrm{~nm}$. The wavelength of the fluorescence peak remains unchanged as phenol concentration between $0.2 \mathrm{mg} / \mathrm{L}$ to $1.0 \mathrm{mg} / \mathrm{L}$.

Assume that $270 \mathrm{~nm} / 290 \mathrm{~nm}$ is the identifiable wavelength of phenol. The maximum of the fluorescence intensity corresponding the excitation wavelength $270 \mathrm{~nm}$ and emission wavelength $300-350 \mathrm{~nm}$ is extracted from the matrix generated after the 3D fluorescence scanning of a series samples of concentration gradient. The diagram of the maximum and the concentration of phenol is shown below.

It can be seen that, when phenol is at a lower concentration, the offset of the curve disappeared, and the correlation between fluorescence intensity and phenol concentration is improved significantly, with the correlation coefficient increasing from 0.9947 to 0.9998 . One possible reason is that the maximum fluorescence intensity of phenol at a low concentration is lower than which of river water at the nearby area. When the excitation wavelength is defined at $270 \mathrm{~nm}$, the influence of river water is eliminated. As a result, the correlation coefficient is improved.

The characteristic wavelength of the peak II of river

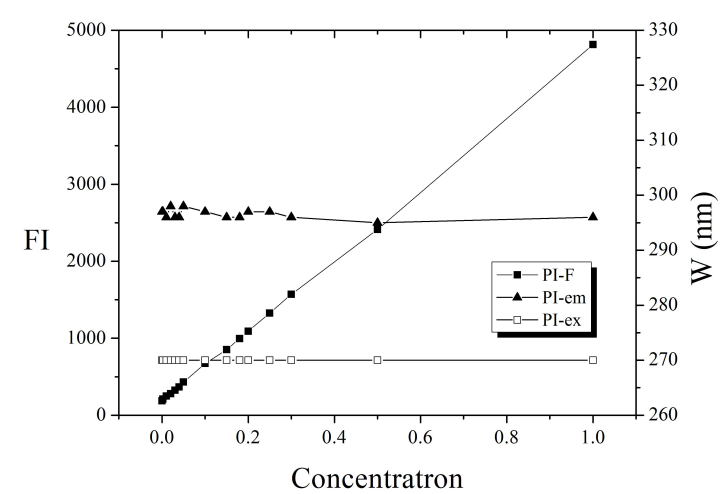

Figure 5. phenol-Forth Bridge protein-like fluorescence peak drawn from excitation wavelength $270 \mathrm{~nm}$

water without phenol is $340 \mathrm{~nm} / 415-430 \mathrm{~nm}$, belonging to the class of humic-like peaks. With the increase of the concentration of phenol, the excitation wavelength of peak II remains unchanged, stable at $340 \mathrm{~nm}$, and emission wavelength fluctuates slightly with the increasing concentration, yet is still located around $430 \mathrm{~nm}$. There is a slight change of fluorescence intensity of peak II with the concentration fluctuations, it can be drawn that there' $\mathrm{s}$ little relation between the concentration of phenol and the fluorescence intensity of peak II. Or we can say that the humic comes from river water itself.

\section{Phenol water fluorescence characteristics and feasibility analysis for its concentration}

When it comes to analyze the characteristics of dissolved organic matter (DOM) of fluorescence, many scholars may prepare the solutions with distilled water, and get better linearity relationship between concentration of

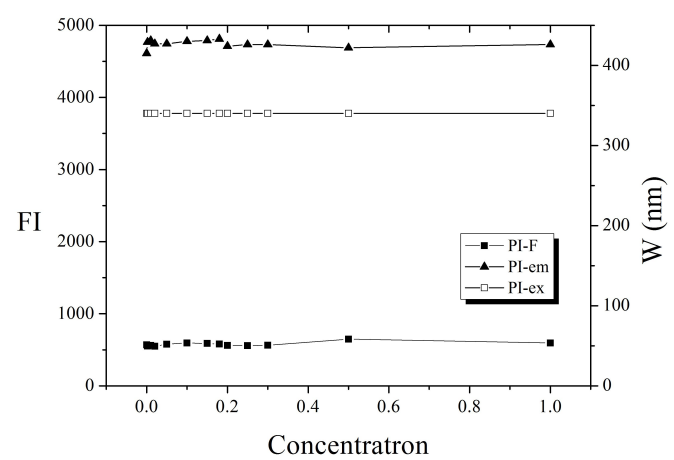

Figure 6. phenol-Forth Bridge humic-like fluorescence peak

and fluorescence intensity. In fact, the existence of some other DOM in river water of fluorescence may have influence on the target material research on different degrees. In our study, there is a good linear relation between the concentration of phenol solution prepared with distilled water and the fluorescence intensity. However, correlation of the concentration of phenol solution prepared with river water and fluorescence intensity will decrease when the concentration is under 0.2 $\mathrm{mg} / \mathrm{L}$.

In reality, fluorospectro photometer can be applied to the detection of phenol in river water for emergency situations. Take the water in Qiantang River for instance, the relationship between phenol concentration and fluorescence intensity is affected by some other DOM of fluorescence in water. When the concentration of phenol is greater than $0.2 \mathrm{mg} / \mathrm{L}$, the correlation coefficient of fluorescence intensity and concentration is 0.999 , the detection of phenol is available above that range. When the concentration is less than $0.2 \mathrm{mg} / \mathrm{L}$, the relationship between fluorescence intensity and concentration of phenol is affected significantly by some other DOM in river water. By drawing the maximum of the fluorescence intensity on the identifiable wavelength of phenol, we can get a new diagram which shows better correlation between the concentration and fluorescence intensity. By this way, we can still detect the accurate concentration of phenol in river water in a very small concentration regardless of the influence of other DOM of fluorescence.

\section{CONCLUSIONS}

Following conclusions can be drawn from this research

- With the concentration of phenol increases, the color of the fluorescence is getting darker, which means the fluorescence peak is a representation of the concentration of phenol in a way.

- When the concentration of phenol in river water is under $0.2 \mathrm{mg} / \mathrm{L}$, the position of the fluorescence peak will shift, leading the relationship between fluorescence intensity and concentration of phenol changed, which is caused by some other DOM in river water.

- By drawing the maximum of the fluorescence intensity on the identifiable wavelength of phenol, we can get a new diagram which shows better correlation between the concentration of phenol and fluorescence intensity, with the correlation of $r$ $=0.9998$. 
- It is practicable to use fluorospectro photometer to detect the concentration of phenol in water rapidly and conveniently.

\section{ACKNOWLEDGMENT}

This reserch was supported by Project of Science and Technology of Zhejiang Innovation Team. We do appreciate what they have offered for this research.

\section{REFERENCES}

[1] HAN X, HUANG T. Statistical analysis of sudden water pollution accidents [J]. Water Resources Protection, 2010, 1: 021.

[2] Su S, Li D, Zhang Q, et al. Temporal trend and source apportionment of water pollution in different functional zones of Qiantang River, China[J]. Water research, 2011, 45(4): 1781-1795.

[3] Michałowicz J, Duda W. Phenols - sources and toxicity[J]. Polish Journal of Environmental Studies, 2007, 16(3): 347-362.

[4] Elina Bastos Caramao, Iraja do Nascimento Filho . Quantitative analysis of phenol and alkylphenols in brazilian coaltar [ J] .Quimica Nova, 2004, 27( 2) : 193 195

[5] G. Boatto , M. Nieddu, A. Carta et al . . Determination of phenol and o- cresol by $\mathrm{GC} / \mathrm{MS}$ in a fatal poisoning case [ J] For ensic Science I nternational, 2004, 139( 2) : 191 194

[6] Shufeng Shen, Zhidong Chang, Huizhou Liu. Three- liquid- phase ex traction systems for separation of phenol and pnitrophenol from wastewater [ J] . Separation and Purification Technology , 2006, 49( 3) : 217 222

[7] Constantine D. Stalikas. Extraction, separation, and detection methods for phenolic acids and flavonoids [ J . J . Sep . Sci . ,2007, 30 ( 18) : 3268 3295

[8] Lin Zhang, Lihua Zhang, Weibing Zhang et al. Analysis of phenols by high- performance liquid chromatography with precolumnder ivaization by 2- ( 9 - car bazole)- ethy-1 chlorofrmate[ J] . Analytica

[9] Baker A. Environment Science \& Technology, 2001, 35( 5) : 948.

[10] Baker A, Curry M. Water Research, 2004, 38( 10) : 2605.

[11] Baker A, Inverarity R. Hydrological Processes, 2004, 18( 15) : 2927.

[12] ZH ONG Run-sheng, ZHANG X-ihui, GUAN Yun-tao, et al Spectroscopy and Spectral Analysis, 2008, 28(2): 347.

[13] Wan g Z G, Liu W Q, Zhao N J, et al. Journal of Environment al Sciences, 2007, 19( 7): 787.

[14] Hur J, Hwang S J, Shin J K. Water Air And Soil Pollution, 2008, 191( 1 - 4) : 231

[15] Cowgill R W. Fluorescence and protein structure: X. Reappraisal of solvent and structural effects[J]. Biochimica et Biophysica Acta (BBA)-Protein Structure, 1967, 133(1): 6-18.

[16] Baker A. Fluorescence properties of some farm wastes: implications for water quality monitoring[J]. Water Research, 2002, 36(1): 189-195. 